\title{
The Comparative Effect of Online Instruction, Flipped Instruction, and Traditional Instruction on Developing Iranian EFL Learners' Vocabulary Knowledge
}

\author{
Mundir (D), ${ }^{1}$ Alim Al Ayub Ahmed $\left(D,{ }^{2}\right.$ Muhammed Salim Keezhatta $\left(\mathbb{D},{ }^{3}\right.$ \\ Bakhrul Khair Amal (D, ${ }^{4}$ Sandhir Sharma (D), 5 Asaad Jassaim Shanan (D), \\ Muneam Hussein Ali $\mathbb{D}^{7}{ }^{7}$ and Mir Mohammad Farooq Haidari $\mathbb{D i D}^{8}$ \\ ${ }^{1}$ Department of Educational Sciences, UIN KH Achmad Siddiq, Jember City, Indonesia \\ ${ }^{2}$ School of Accounting, Jiujiang University, Qianjin Donglu, Jiujiang, Jiangxi, China \\ ${ }^{3}$ Department of English, College of Science and Humanities in Alkharj, Prince Sattam Bin Abdulaziz University, \\ Alkharj, Saudi Arabia \\ ${ }^{4}$ Universitas Negeri Medan, Medan, Indonesia \\ ${ }^{5}$ Chitkara Business School, Chitkara University, Punjab, India \\ ${ }^{6}$ College of Physical Education and Sport Science, Al-Ayen University, Thi-Qar, Iraq \\ ${ }^{7}$ Al-Nisour University, Baghdad, Iraq \\ ${ }^{8}$ Economic Faculty and Research Deputy, Taj University, Mazar-i-Sharif, Afghanistan
}

Correspondence should be addressed to Mir Mohammad Farooq Haidari; mir.m.farooqhaidari@gmail.com

Received 31 December 2021; Accepted 24 January 2022; Published 10 February 2022

Academic Editor: Ehsan Namaziandost

Copyright ( $(2022$ Mundir et al. This is an open access article distributed under the Creative Commons Attribution License, which permits unrestricted use, distribution, and reproduction in any medium, provided the original work is properly cited.

During the COVID-19 pandemic, using online and flipped instruction is the best alternative for traditional instruction. Therefore, this study compared the effects of three instructions, including online, flipped, and traditional, on improving Iranian EFL learners' vocabulary knowledge. To do so, 90 Iranian intermediate EFL learners were selected among 119 students as the participants of this study. The target participants were randomly divided into three equal groups (online, flipped, and traditional). After that, all groups were pretested by a vocabulary test. Then, the participants of one group received the treatment by using fully online instruction, and the other group participants received a flipped instruction. On the other hand, the participants of the third group received conventional vocabulary instruction. After teaching 100 new English words to all groups with three different instructions, a vocabulary posttest was administered to all participants. The paired samples $t$-test and one-way ANOVA results indicated that both online and flipped groups outperformed the control group in the vocabulary posttest. In addition, the findings revealed the flipped group outflanked the online group in the posttest of vocabulary. The implications of this study can encourage both EFL teachers and learners to integrate the flipped and online instructions into their teaching and learning processes.

\section{Preliminaries}

The COVID-19 pandemic situation has compelled the suspension of all activities that have the potential to generate large crowds, including teaching and learning activities in schools and on college campuses. Due to this, the learning process is conducted entirely online. Digital technology has a significant impact on the breadth of education globally, including in Iran. One example is online learning, conducted through an online system or in a network that utilizes electronic media to facilitate learning [1]. The term "online learning" is defined by Walabe and Rocci Lubicini [2] as courses that effectively use the Internet and technology to provide students with educational advantages. It is not as simple as using technology in education since excessive variables play a role and are interconnected. This is 
consistent with Ali's [3] assertion that technology is the delivery method and that it necessitates tight coordination across instructional, content, and technology teams. Murgatrotd [4] highlights shortcomings such as a lack of online teaching infrastructure, instructor inexperience, an information gap, and a complicated home environment. Of course, suppose we utilize electronic media or technology to conduct learning via online teaching. In that case, Internet data is essential since no one would access online learning without it. Furthermore, Syaifudin [5] underlines that online learning has no time or location constraints as long as it is linked to the Internet.

Dhawan [6] argues that since online learning is studentcentered and provides a great degree of flexibility in terms of time and place, its application in E-learning may significantly impact the overall learning experience. Saleem and Rasheed [7] claim that the primary benefit of online learning is that it increases access to education while simultaneously reducing prices and time commitments and boosting learners' academic achievement.

The other new method that has been used during the COVID-19 pandemic is flipped instruction which is a new teaching strategy that aims to get the students to do exercises outside the classroom milieu, often performed by some electronic methods. As explained by Embi [8], the term "flipped classroom" describes an educational approach in which students are given a chance to learn topics outside of class as well as review content they have already learned in the classroom (p. 198). In a flipped classroom, the emphasis is shifted from the teacher to the student and their progress, allowing for more time devoted to discussion and collaboration [9]. According to the flipped classroom model, students watch teacher-produced videos at home before class and complete homework assignments in the classroom [10].

Flipped instruction, according to Bishop and Verleger [11], refers to a student-centered learning system that is divided between two sections: interactive learning experiences during class time and distinct teaching bases that are entirely reliant on computers. By viewing videos, listening to digital files, and reading articles, learners may prepare themselves for the activity [12]. In the opinion of Jenkins [13], there are several positive aspects of the flipped classroom, including the fact that learners are allowed to access materials and take them in at their own pace, among other things. They may access lecture materials in private by concealing them at home and using a video-based platform to view the contents on their computers. This allows individuals to approach items without being concerned about their friends, recognizing that they are slower or quicker. It is possible for students to analyze materials at their own pace by stopping, pausing, rewinding, and fast-forwarding them $[14,15]$.

Flipped and online instructions can be applied to improve Iranian EFL learners' vocabulary knowledge. An ordinary 12 learner tends to place a high value on expanding his/her vocabulary [16]. According to Pintrich and Schunk [17], English language learners who have a limited vocabulary are less able to understand and communicate with others. Also, in EFL/ESL programs, Nation [18] highlights the significance of vocabulary acquisition. When it comes to mastering the English language, understanding vocabulary is vital. The reason is straightforward: English has one of the most diverse and expansive vocabularies of any language. A complex blend of Germanic and Romance words and vocabulary is an essential factor of language competency since it provides the foundation for how effectively students can talk, listen, read, and write. Learning a new language may be a frustrating experience if you do not have the proper vocabulary techniques [19].

Regarding the importance of vocabulary in learning the English language, the present research intended to examine the effects of online, flipped, and traditional instructions on boosting Iranian EFL learners' vocabulary knowledge. This study can be significant since it compared the effectiveness of three different instructions on vocabulary learning of 90 Iranian EFL learners' vocabulary enhancement during the pandemic of the COVID-19.

\section{Review of the Literature}

2.1. Theoretical Background. Since the COVID-19 outbreak, several governments have implemented lockdown and social distance measures that have forced the closure of schools, training institutes, and higher education institutions. Educators are rethinking their methods of delivering highquality education through different online channels. Despite the difficulties presented to both teachers and students, it has become a remedy for this unprecedented worldwide epidemic [20]. Transitioning to online learning may be a new experience for both instructors and learners, which they must adjust to with few or no other options. As a result of numerous Internet platforms, the educational system and teachers have accepted "Education in Emergency" and are now forced to implement a system for which they are unprepared [21].

Schools and colleges have used online technologies to keep students engaged throughout this epidemic, which has resulted in the closure of several institutions of higher learning [22]. Staff and student preparation for the new adjustments must be assessed and appropriately encouraged. Students with a static mentality have a tough time modifying and adjusting to new learning environments, but students with a strong mentality adapt fast. Online learning methodology cannot be standardized. There is a wide range of topics, each with different requirements. Subjects and age groups need distinct strategies for online education [23]. Learners with physical disabilities may also benefit from online learning since it enables them to engage in the virtual classroom without forcing them to move around much $[20,24]$.

Besides fully online instruction, flipped instruction has been used widely during the COVID-19 pandemic. Students' active participation, cooperation, and support are hoped to increase via more efficient teaching time in a flipped learning approach $[9,25]$. Recently, teaching and research have been paying increasing attention to the flipped learning model. An instructor may use video lectures or screencasts to 
illustrate a topic's central idea to learners, allowing class time for greater student activity participation under the leadership of the teacher in a flipped classroom [26].

According to O'Flaherty and Phillips [27], flipped learning is a blended learning technique that flips the conventional university teaching and learning paradigm on its head. During a flipped classroom, didactic lectures, which are typically delivered in person, are prerecorded and made available for students to watch before in class, while chances to strengthen, broaden, and implement students' comprehension of the recorded material are provided through the use of "active learning strategies" during the class time [28].

Flipped learning also differs in that learners first learn about new course material outside of class and then spend time in class consolidating what they have learned [29]. The flipped learning method encourages students to access lecture videos at home and participate in learning activities to comprehend the material better. Learners can obtain lectures conveniently since they are recorded in videos and maybe accessed practically entirely online. The videos may also be paused or replayed if necessary [30]. Learners take notes on their questions and bring them up in class, even if the instructor does not directly answer them. As a result, learners benefit from this strategy in increasing their motivation and achievement [31].

The complete learning framework is flipped in flipped learning, which is why it is termed flipped learning. That is, the assignment is completed in the classroom, and the lecture is presented to learners before class time [32]. The fundamental purpose of flipping the learning is to improve the face-to-face interaction between professors and learners and allocate class time spent talking about issues, responding to questions, and doing activities [33].

2.2. Experimental Background. Some studies were performed regarding the flipped and online instructions; for example, Zarei and Asadi Amani [34] investigated the impact of different online strategies (word reference, media, and vocabulary games) on reading comprehension and vocabulary comprehension and production. To do this, 60 language learners were selected and divided into 3 groups, with each group being allocated to one of the treatment conditions at random. The pretest for the study was administered at the first session of therapy, and it consisted of a vocabulary test. Language learners in the 3 groups received instruction via online vocabulary games, online media, transcripts, and online word references while undergoing treatment. The posttests were administered after the intervention and consisted of a reading comprehension exam, a vocabulary comprehension test, and a vocabulary production test. Three one-way ANOVA techniques were used to assess the data that had been acquired. Overall, it was determined that the Internet media group outperformed the other organizations. Based on the findings of this research, it is possible to infer that various online tools may have varied effects on multiple areas of language acquisition when used in conjunction.
Regarding vocabulary accomplishment, Khodaparast and Ghafournia [35] investigated whether online, offline, and hybrid techniques had any meaningful impact on Iranian EFL learners' achievement in an educational program. Students from the Islamic Azad University of Ahvaz, majoring in English Teaching, made up the majority of the 100 participants. The participants had a language skill level above the upper intermediate level. They were given a vocabulary pretest and a vocabulary posttest. The findings showed a statistically significant difference between the conventional technique and the other three ways studied. In other words, computer-assisted teaching methodologies had a considerable impact on the vocabulary development of language learners. The data also demonstrated that using a mixed strategy substantially boosted L2 vocabulary success in the students. The results suggested that language learners who were taught using CALL techniques had higher levels of self-assurance than the other students studied.

Mahmoudi [36] inspected the impacts of online instruction via smartphone on Iranian EFL students' grammatical accuracy enhancement. Two groups of upperintermediate students, including one experimental group and one control group, were selected to achieve this objective. The traditional instruction was utilized in teaching grammar to the control respondents, while the online instruction was used to teach the experimental group. The outcomes depicted that there were noticeable differences between the experimental and the control participants, and the experimental participants outflanked the control group after the treatment.

A study conducted by Abbasi et al. [37] examined the improvement of oral communication skills using online strategy-based education. To achieve this, 80 Iranian female and male students studying at the intermediate level participated in the therapy. They were separated into four groups of twenty people each. Instructing participants in social and emotional techniques was beneficial to both the experimental and control groups. Pre- and posttest designs were used to assess the therapy's effectiveness and compare the results. Because of this, the data was examined using oneway ANOVAs and I-tests to uncover patterns. The results demonstrated that the strategy treatment effectively increased the participants' verbal capacity. The performance of the male and female treatment groups, on the other hand, did not vary significantly from one another. Because of this, the results indicated that online strategy-based training might have a favorable impact on the speaking skills of Iranian intermediate EFL learners.

Khoiriyah [38] examined the effects of the flipped classroom on enhancing EFL students' listening skills. Furthermore, the purpose of this research was to understand the students' perceptions of their experience in a flipped classroom. An online open-ended questionnaire and the pre- and posttreatment tests were used in conjunction with an online open-ended questionnaire to create a mixed approach. According to the findings of this research, the average score on the posttest was considerably higher than the average score on the pretest, showing that flipped teaching improved the students' listening comprehension skills. 
Furthermore, most students expressed satisfaction with their flipped classroom experience in their written responses.

Iranian students' vocabulary acquisition was researched by Rezai Fard et al. [39]. They found that teaching ESP vocabulary through the flipped classroom improved Iranian students' vocabulary learning. It was also determined what the views of ESP learners were regarding using the flipped classroom format throughout the research process. To gather and evaluate the data in this research, a quantitative approach was used to collect and analyze the data. This resulted in the nonrandom selection of 60 ESP participants studying English at Payame Noor University, chosen based on their performance on the OQPT. An initial pretest was delivered to all of the participants, and they were then separated into two equal groups, each consisting of 30 people. Instruction was given in a flipped classroom to the participants in the experimental group. The control group got vocabulary education using a traditional technique widely used at the institution where it was conducted. A posttest was administered to both groups of participants to assess the students' progress in acquiring a new language. An anonymous 10item questionnaire was sent to the participants following the treatment phase of the study to determine their opinions regarding utilizing the flipped classroom. The results were used to develop recommendations for future research. The one-way MANOVA revealed that flipping classes substantially impacted Iranian students' vocabulary development in English as a second language course. The participants in the experimental group also agreed that deploying flipped classrooms had a beneficial impact on their attitudes about ESP courses.

Sudarmaji et al. [40] studied the impacts of the flipped classroom model on students' speaking skills. To do this research, 34 senior high school students were chosen as the research participants. The subjects were assigned to two groups: control and experimental. A speaking test was done before and after implementing the flipped classroom model to determine the students' speaking performances. The outcomes revealed that the online flipped classroom model significantly developed the students' speaking performances.

Hashemifardnia et al. [41] inspected the effect of utilizing flipped classrooms on helping EFL students develop their speaking CAF. To achieve this purpose, 60 intermediate EFL learners were chosen and assigned to flipped and nonflipped. Then, all participants were administered a speaking pretest. Later, the flipped participants received the treatment via flipped-based instruction, but the nonflipped participants were traditionally trained. At the end of the treatment, an attitude questionnaire was given to the flipped participants to check their opinions about applying to the flipped classroom. The outcomes proved that the flipped group did better than the nonplipped group on the speaking posttest. In addition, the findings revealed that the participants presented desirable attitudes toward using flipped instruction in English language learning.

Using the flipped classroom paradigm, Rajabi et al. [42] looked into the impacts of classroom anxiety and listening performance on Iranian EFL learners' performance in class. This was accomplished by selecting 68 Iranian EFL learners based on their results on the Oxford Placement Test (OPT) and the random division of each into an experimental (flipped group) and a control group, each of which had 34 participants. A classroom anxiety measure and the listening portion of a preliminary English language exam were administered to both groups before the commencement of the therapy (PET). The experimental group got the instructional materials and video podcasts over the WhatsApp messaging app. They were instructed to review the items relevant to the target instruction before attending the course. Each of the audio recordings was played once or twice in the classroom for the control group. In the last step, both groups were administered the classroom anxiety scale and the listening portion of the PET, which served as the posttests for both groups. The data analysis findings revealed that there was no statistically significant difference between the two groups in terms of their anxiety levels. Because of this, the experimental group received better marks on the listening performance exam when compared to the control group, indicating that the flipped classroom approach may improve the listening skills of Iranian EFL learners.

Despite the importance of online-based instruction and flipped instruction, they are less used in teaching and learning English in Iranian EFL contexts. Most English classes are held in a face-to-face situation rather than through online instructions. In light of the fact that these novel instructions have received little attention in the Iranian EFL context, the purpose of this study was to investigate the effects of these teaching modes on the vocabulary knowledge of Iranian EFL learners. Consequently, this research attempted to answer the following question:

RQ. Are there any significant differences between the effectiveness of the online instruction, the flipped instruction, and the traditional instruction on enhancing Iranian intermediate EFL learners' vocabulary knowledge?

\section{Methods}

3.1. Participants. To carry out this investigation, 90 Iranian EFL students were chosen among 119 learners through a convenience sampling method. They were selected from two English Language Institutes in Ahvaz, Iran. Their English level was intermediate, determined based on their band score on the Oxford Quick Placement Test (OQPT). The selected respondents were all males with the age range of 19 to 31 years old. They were randomly assigned to two experimental groups of online and flipped and a traditional or a control group.

3.2. Instrumentation. The first tool employed in the current research to make the subjects homogenous was the OQPT. It was used to assist the researchers in getting an exact comprehension of what levels (i.e., elementary, preintermediate, intermediate, and advanced) the respondents were at. This instrument included 60 multiple-choice questions, and according to its results, the students who scored between 40 and 47 were intermediate and considered the target sample of this research. 
The second tool applied in the present research was a pretest of vocabulary, which the researchers designed. The pretest included 20 multiple-choice items from the students' coursebooks. The reliability and the validity of the test were calculated. In fact, three English professors checked the face and the content validity of the pretest. That is, to make sure about the Content Validity Index (CVI) of the test questions, three English university instructors inspected the test and recommended a few changes regarding the clarity, the simplicity, and the representativeness of questions. As a result, the researcher modified some questions of the test, and then she piloted it on 15 students with similar characteristics to the target groups. Then, the pretest reliability was measured by utilizing the KR-21 formula $(r=0.87)$.

The other tool employed in this research was a posttest for measuring vocabulary knowledge after the treatment. The researcher modified some items of the pretest and used it as the posttest of this research. Most features of the posttest were similar to the characteristics of the pretest, including number, content, and type of the questions. The researcher made a subtle difference (changing the orders and the options of the questions) to hinder the possible recall of the answers of the pretest. The posttest was conducted to assess the effects of the treatment on the vocabulary development of the participants. A group of English experts validated the posttest, and its reliability was determined by applying the KR-21 formula $(r=0.89)$.

3.3. Procedures. To perform this research, 90 Persian EFL students from two English Language Institutes of Ahvaz, Iran, were chosen. After that, the participants were randomly assigned to three groups: two experimental and one control. A researcher-designed vocabulary test pretested the three groups, and then, the instruction was conducted on them differently. As the instruction, the participants of one experimental group were taught only online by applying the Skype application. The researcher taught ten vocabulary items in each online session to this group. The meanings, the synonyms, the antonyms, and even the explanations of the words were provided by the students either in a voice format or in a written format. Example sentences were also sent to the group to assist the learners in learning the words better. The students could ask their questions and share their ideas and knowledge in the group. The researcher immediately gave feedback on the students' ideas and comments. At the outset of each session, one vocabulary quiz was given to this group to encourage them to read the words more.

The students in the flipped group were sent the vocabulary items online, and they were chargeable for their learning. The researcher did not teach them online; he only sent the materials and required the students to study them both in pairs and individually before coming to the face-toface classroom. The researcher used the WhatsApp application to send the materials to the students of this group. In the flipped group, the researcher put more responsibility for interacting and viewing with content on the learners, and the formative assessments were utilized after each session. In the flipped class, the teacher moved from being the "sage on the stage" to the "guide on the side" via supplying individualized assistance for all students. In this class, the researcher gave the participants time to watch the videos or read the texts in the classroom; the learners then did the follow-up activities, with the teacher supplying assistance and direction as necessary.

The control group participants were trained in the vocabularies in a conventional classroom. The researcher did not use any online-based tools and activities to teach the vocabulary items to the control group. The researcher translated the words into Persian and provided the Persian equivalent of each word. He also offered example sentences and required the students to practice the words at home. At the beginning of each session, one vocabulary quiz was administered to the control group. This procedure continued to teach all one hundred words. After the treatment ended, a vocabulary posttest was administered to the three groups to check the effects of the online, the flipped, and the traditional instructions on the students' vocabulary enhancement.

3.4. Data Analyses. After collecting the needed data via applying the above-used tools, we analyzed them based on the purposes of the research. The statistical tools, including one-way ANOVA and post hoc Scheffe tests, were used to measure the impacts of the instruction on vocabulary learning of the participants.

\section{Results of the Study}

After gathering the needed data, the researchers analyzed them to get the final results. Since we had three groups, oneway ANOVA was used to analyze the scores of the vocabulary pre- and posttests. The details of the results are displayed in Tables 1-5.

In Table 1, the mean scores and the standard deviations of the three groups are displayed. The mean scores of the experimental groups, online and flipped, are 13.96 and 15.06 , respectively. Based on this table, the traditional group's mean score is 14.53 , implying that all groups had almost the same vocabulary knowledge at the outset of the treatment.

Based on Table 2, Sig is 0.20, which is higher than 0.05; thus, the differences between the vocabulary pretests of the experimental groups and the traditional group were not significant; indeed, both groups had equal performances in the pretest of vocabulary.

Table 3 depicts the mean scores and the standard deviations of the three groups in the vocabulary posttests. The means of the online and the flipped groups are 17.93 and 19.50 , respectively, and the mean of the traditional group is 15.36. Seemingly, both experimental groups had better performances than the traditional group in the vocabulary posttest. Table 4 shows if the differences between the vocabulary posttests of the three groups are remarkable or not.

According to Table 4, Sig (.00) is smaller than 0.05, meaning that there are noticeable differences between the vocabulary posttests of the three groups in favor of the experimental groups. 
TABLE 1: Descriptive statistics of the groups in the vocabulary pretest.

\begin{tabular}{lcccccccc}
\hline & & & & & \multicolumn{2}{c}{$95 \%$ confidence interval for } \\
& $N$ & Mean & Std. deviations & Std. errors & \multicolumn{2}{c}{ means } & Minimum & Maximum \\
& & & & & Lower bound & Upper bound \\
\hline Traditional & 30 & 14.53 & 1.99 & 0.36 & 13.78 & 15.27 & 11.00 \\
Online & 30 & 13.96 & 2.61 & 0.47 & 12.98 & 14.94 & 10.00 \\
Flipped & 30 & 15.06 & 2.47 & 0.45 & 14.14 & 15.99 & 11.00 \\
Total & 90 & 14.52 & 2.39 & 0.25 & 14.02 & 15.02 & 10.00 \\
\hline
\end{tabular}

TABLE 2: One-way ANOVA (pretest of vocabulary).

\begin{tabular}{lccccc}
\hline & Sum of square & Df & Mean squares & $F$ & Sig. \\
\hline Between groups & 18.15 & 2 & 9.07 & 1.60 & 0.20 \\
Within groups & 492.30 & 87 & 5.65 & \\
Total & 510.45 & 89 & & \\
\hline
\end{tabular}

TABLE 3: Descriptive statistics of the groups in the vocabulary posttest.

\begin{tabular}{lccccccc}
\hline & & & & & \multicolumn{2}{c}{$95 \%$ confidence interval for } \\
& $N$ & Mean & Std. deviations & Std. errors & \multicolumn{2}{c}{ means } & Minimum \\
& & & & & Lower bound & Upper bound & \\
\hline Traditional & 30 & 15.36 & 1.56 & 0.28 & 14.78 & 15.95 & 13.00 \\
Online & 30 & 17.93 & 1.46 & 0.26 & 17.38 & 18.47 & 15.00 \\
Flipped & 30 & 19.50 & 1.00 & 0.18 & 19.12 & 19.87 & 16.00 \\
Total & 90 & 17.60 & 2.18 & 0.22 & 17.14 & 18.05 & 13.00 \\
\hline
\end{tabular}

TABle 4: One-way ANOVA (vocabulary posttest).

\begin{tabular}{lccccc}
\hline & Sum of square & df & Mean squares & $F$ & Sig. \\
\hline Between groups & 261.26 & 2 & 130.63 & 70.01 & 0.00 \\
Within groups & 162.33 & 87 & 1.86 & \\
Total & 423.60 & 89 & & \\
\hline
\end{tabular}

The findings of the post hoc Scheffe test in Table 5 confirm that the differences between the traditional group's posttest scores and both experimental groups are significant. Similarly, the differences between the posttest scores of the experimental groups are remarkable in favor of the flipped group.

\section{Discussion and Conclusion}

To answer the research question "Are there any significant differences between the effectiveness of the online instruction, the flipped instruction, and the traditional instruction on enhancing Iranian intermediate EFL learners' vocabulary knowledge?", one-way ANOVA test was used, and its findings indicated that those groups who had received the treatment by using the flipped and the online instructions conducted significantly better than those whose instruction was done traditionally. Moreover, the results indicated that the flipped group outflanked the online group in the posttest. According to the gained outcomes, both experimental participants had an improvement in their posttests, but the flipped group had the best performance among the three groups.

The obtained results are in line with Zarei and Asadi Amani [34], who showed that online instruction developed the experimental group's reading comprehension, vocabulary comprehension, and production. Moreover, the findings of the research are confirmed by Abbasi et al. [37], who indicated that online-based instruction could greatly affect the speaking abilities of their participants.

The better performances of the students who utilized the flipped and the online instructions can refer to the fact that they had more interactions. Interactions and technologies assisted EFL students' development in learning vocabulary [43].

The findings of this research indicated that the flipped participants had better performances than the online participants. This part of the results is supported by Khodaparast and Ghafournia [35], who examined if online, offline, and blended methods produced any remarkable effects on vocabulary knowledge of Iranian EFL students and demonstrated that the blended approach was more effective than the other approaches. Also, our study is advocated by Khoiriyah [38], who indicated that flipped instruction developed the listening comprehension skills of English learners.

The outcomes of the current research are in accordance with Abaeian and Samadi [44], who investigated the effect of the flipped classroom on Iranian EFL students' reading skills and indicated that the experimental participants did better than the control participants in the posttest. Furthermore, this investigation is advocated by Rajabi et al. [42] who inspected the effects of the flipped instruction model on 
TABle 5: Post hoc Scheffe test and multiple comparisons (posttest of vocabulary).

\begin{tabular}{|c|c|c|c|c|c|c|}
\hline \multirow{2}{*}{ (I) groups } & \multirow{2}{*}{ (J) groups } & \multirow{2}{*}{ Mean difference (I-J) } & \multirow{2}{*}{ Std. errors } & \multirow{2}{*}{ Sig. } & \multicolumn{2}{|c|}{ 95\% confidence interval } \\
\hline & & & & & Lower bound & Upper bound \\
\hline \multirow{2}{*}{ Traditional } & Online & $-2.56^{*}$ & 0.35 & 0.00 & -3.44 & -1.68 \\
\hline & Flipped & $-4.13^{*}$ & 0.35 & 0.00 & -5.01 & -3.25 \\
\hline \multirow{2}{*}{ Online } & Traditional & $2.56^{*}$ & 0.35 & 0.00 & 1.68 & 3.44 \\
\hline & Flipped & $-1.56^{*}$ & 0.35 & 0.00 & -2.44 & -.68 \\
\hline \multirow{2}{*}{ Flipped } & Traditional & $4.13^{*}$ & 0.35 & 0.00 & 3.25 & 5.01 \\
\hline & Online & $1.56^{*}$ & 0.35 & 0.00 & 0.68 & 2.44 \\
\hline
\end{tabular}

*The mean differences are significant at the 0.05 level.

Iranian EFL students' listening performance. The findings of the research indicated that the experimental participants obtained better scores in the listening skill test, meaning that the flipped classroom model could enhance Iranian EFL students' listening skills. Also, this study is in line with Sarani et al. [45], who examined the effects of flipped instruction on Iranian EFL learners' writing skill improvement at senior high school. Their outcomes revealed that the flipped group performed better than the control group on the writing posttest.

The results of the study indicated that the flipped group outflanked the online group in learning vocabulary. We can ascribe this betterment to the advantages of flipped instruction that provides preclass materials in the forms of audio and videotaped files. The learners have the opportunities to read these materials to learn the novel vocabularies of the lessons. It is believed that learning vocabularies need several resources, and more exposure to contextual inputs is an essential agent in teaching vocabulary [46]. Learning vocabulary is not an easy task, and it needs a lot of attention and practice from the side of the students.

One reason why the flipped group outperformed the other groups is that while learners of the flipped group applied different out-of-class educational resources, they became more ready in the classes, and the time of the class was spent on higher-order cognitive tasks rather than just concentrating on countless language forms. In this way, the lower order cognitive tasks such as comprehending and recalling were conducted before the classes, and students had much time to learn deeply before attending the classroom. Afterward, the upper-level cognitive tasks such as using, analyzing, assessing, and creating were performed through the support and the presence of the instructors and other learners at the time of the class.

The other reason for the gained findings is that flipped instruction can activate cooperation rather than competition among the learners. This model puts emphasis on collaborative learning that assists learners to improve their skills of higher-order thinking. In addition, flipped instruction can free the educational time and prepare the ground for interactive learning tasks that enhance pupils' communicative competencies. Here, one can claim that the student-oriented feature and the flipped instruction's collaborative nature can prepare the learners to improve their vocabulary knowledge.

One more reason for the obtained results can be ascribed to the nature of the flipped instruction that is following the educational procedures that put learners at the center of the learning process by forcing them accountable for their previous experiences with learning autonomously before attending the actual classes. Harris et al. [47] asserted that flipped instruction puts the instructional encumbrances upon the learners; teachers get the experts who improve the abilities of their pupils and remove the codependency ( $p$. 331). Unlike a conventional classroom that causes codependency, flipped instruction makes independency for stimulating learners to resolve their difficulties.

The findings of this investigation corroborate the theoretical idea that flipped courses allow simple access to material teaching via mobile tools, videos, and the Internet. The flipped instruction provides the active uses of the class time; it enables learners to move at their speed, and in case they are unable to take part in the classes because of some reasons, they are provided with an opportunity to learn about subjects which are instructed out of the class contexts [48, 49].

Our study supports the online collaborative learning theory proposed by Harasim [50], stating that implementing the Internet and online learning in teaching and learning can produce positive and contributive effects. Based on this theory, students can solve their learning problems cooperatively, leading to better English learning.

Looking back at the outcomes, it can be concluded that flipped instruction and fully online instruction are more effective than traditional instruction. The conclusion to be made here is that instructors have to apply an amalgamation of these instructions. Various methods and strategies in language teaching can significantly help language learners enhance their vocabulary knowledge. Among these approaches and techniques, technological tools have been shown to affect how language learners communicate, generate ideas, and manage their communications. Online tools like online English language learning websites, online dictionaries, chatting and emails, online games, presentation software, and online media can result in better learning findings and play a crucial role in providing less anxiety-provoking and more motivating and enjoyable environments where learners can focus on new words and how they are utilized [51].

The implications of this study can encourage EFL learners to apply online games, online dictionaries, and online media to increase their range of vocabulary. The combination of the traditional methods and the online tools may be more effective in helping a larger number of learners to overcome their learning problems. The findings of this study can help students to learn English both in and outside of the class environment. The results of this research can 
encourage EFL teachers to implement different types of instructions (flipped and online) in their classes to produce better learning results. The findings of the present study are helpful for teachers in making them aware of the importance of using online education in their classes to help learners overcome their anxiety and increase their language proficiency. By applying innovative strategies such as the flipped and the online instructions, EFL materials designers can create more personalized educational materials meeting the requirements of language students with various learning styles and attitudes. Applying technology aids them in designing multimodal materials to make language learners more interested in language learning.

There are some limitations in the present research; the main one is the small sample of the study that was only 90 Iranian EFL students. Upcoming investigations are recommended to add more respondents to promote the validity and reliability of their results. This study used only quantitative data to answer the question posed in the research; other researchers are offered to use the qualitative data as well to enrich the findings of their studies. This study could cover only one dependent variable (vocabulary learning); subsequent investigations can investigate the impacts of the online and the flipped instructions on other skills and subskills of English. The convenience sampling method was used in this study, so the researchers selected the population close to hand; future research can use other sampling methods to collect more valid data.

\section{Data Availability}

The data are available upon request with the corresponding author.

\section{Conflicts of Interest}

The authors declare that they have no conflicts of interest.

\section{References}

[1] B. Rahmawati, C. Sihombing, E. K. B. Ginting, and E. Arimonnaria, "The effect of e-learning on students speaking skill progress: a case of the seventh grade at SMP Pencawan Medan," Indonesian EFL Journal, vol. 7, no. 1, pp. 69-78, 2021.

[2] M. Walabe and G. Rocci Lubicini, "E-learning refers to courses that use technology and the internet to provide constructive e-learning opportunities to students," IJEDE Journal, vol. 35, no. 2, pp. 77-89, 2020.

[3] W. Ali, "Online and remote learning in higher education institutes: a necessity in light of COVID-19 pandemic," Higher Education Studies, vol. 10, no. 3, pp. 16-25, 2020.

[4] S. Murgatrotd, "COVID-19 and Online learning, Alberta, Canada," 2020.

[5] M. Syaifudin, "Improving students speaking skill by implementing blended learning (online learning and classroom)," Informa Politeknik Indonusa Surakarta Journal, vol. 3, no. 2, pp. 54-68, 2017.

[6] S. Dhawan, "Online learning: a panacea in the time of COVID-19 crisis," Journal of Educational Technology, vol. 49, no. 1, pp. 5-22, 2020.
[7] M. A. Saleem and I. Rasheed, "Use of e-learning and its effect on students," New media and Mass Communication, vol. 2, no. 6, pp. 110-125, 2014.

[8] M. A. Embi, Blended and Flipped Learning: Case Studies in Malaysian HEIs. Selangor: Centre for Teaching and Learning Technologies, University Kebangsaan Malaysia, Bangi, Malaysia, 2014.

[9] J. Bergmann and A. Sams, Flip Your Classroom: Reach Every Student in Every Class Every Day, Internal Society for Technology in Education, Washington, DC, USA, 2012.

[10] H. Witten, "World languages," in Flipping 2.0: Practical Strategies for Flipping Your Class, J. Bretzman, Ed., pp. 26280, The Bretzman Group, New Berlin, WI, USA, 2013.

[11] J. L. Bishop and M. A. Verleger, "The flipped classroom: a survey of the research," in Proceedings of the 120th ASEE Annual Conference and Exposition, Atlanta: GA, USA, 2013.

[12] B. Mull, "Flipped learning: a response to five common criticisms," 2012, http://novemberlearning.com/resources/ articles/flippedlearning-a-response-ofivecommoncriticisms.

[13] C. Jenkins, "The Advantages and disadvantages of the flipped classroom," 2012, http://info.lecturetools.com/blog/bid/ 59158/The-Advantages-and-Disadvantages-of the-FlippedClassroom.

[14] C. Anwar and A. Pratama, "Flipped classroom in teaching speaking to young learners," in Proceedings of the 63rd TEFLIN International Conference, Universitas PGRI, Adi Buana, Indonesia, 2016.

[15] S. V. Vadivu and S. Chupradit, "Psychosocial and occupational impact assessment due to internet addiction: a critical review," Systematic Reviews in Pharmacy, vol. 11, no. 7, pp. $152-155,2020$.

[16] C. B. Zimmerman, "Historical trends in second language vocabulary instruction," in Second Language Vocabulary Acquisition, pp. 5-19, Shanghai Foreign WBLL, Shanghai, China, 2001.

[17] P. R. Pintrich and D. H. Schunk, Motivation in Education: Theory, Research, and Applications, Merrill Prentice-Hall, Upper Saddle River, NJ, 2nd edition, 2002.

[18] I. S. P. Nation, Learning Vocabulary in Another Language, Cambridge University Press, Cambridge, UK, 2001.

[19] B. Gorjian, M. Alipour, and R. Saffarian, "The effect of multisensory techniques on reading comprehension among pre-intermediate EFL learners: the case of gender," Advances in Asian Social Science, vol. 1, no. 2, pp. 192-196, 2012.

[20] G. Basilaia and D. Kvavadze, "Transition to online education in schools during a SARS-CoV-2 coronavirus (COVID-19) pandemic in Georgia," Pedagogical Research, vol. 5, no. 4, p. 10, 2020.

[21] S. Pokhrel and R. Chhetri, "A literature review on impact of COVID-19 pandemic on teaching and learning," Higher Education for the Future, vol. 8, no. 1, pp. 133-141, 2021.

[22] S. Subedi, S. Nayaju, S. Subedi, S. K. Shah, and J. M. Shah, "Impact of e-learning during COVID-19 pandemic among nourishing students and teachers of Nepal," International Journal of Science and Healthcare Research, vol. 5, no. 3, pp. 9-25, 2020.

[23] A. Doucet, D. Netolicky, K. Timmers, and F. J. Tuscano, "Thinking about pedagogy in an unfolding pandemic: an independent report on approaches to distance learning during COVID19 school closures," 2020, https://issuu.com/ educationinternational/docs/2020-research-covid-19-eng.

[24] K. Seneviratne, J. A. Hamid, A. Khatibi, F. Azam, and S. Sudasinghe, "Multi-faceted professional development designs for science teachers' self-efficacy for inquiry-based 
teaching: a critical review," Universal Journal of Educational Research, vol. 7, no. 7, pp. 1595-1611, 2019.

[25] A. Gunasinghe, J. A. Hamid, A. Khatibi, and S. M. Ferdous, "The viability of UTAUT-3 in understanding the lecturer's acceptance and use of virtual learning environments," International Journal of Technology Enhanced Learning, vol. 12, no. 4, pp. 458-481, 2020.

[26] N. B. Milman, "The flipped classroom strategy: what is it and how can it best be used?" Distance Learning, vol. 9, no. 3, pp. 85-87, 2012.

[27] J. O'Flaherty and C. Phillips, "The use of flipped classrooms in higher education: a scoping review," The internet and higher education, vol. 25, pp. 85-95, 2015.

[28] Z. Zainuddin and S. H. Halili, "Flipped classroom research and trends from different fields of study," International Review of Research in Open and Distance Learning, vol. 17, no. 3, pp. 313-340, 2016.

[29] C. Brame, "Flipping the classroom. Vanderbilt university Center for teaching," 2013, http://cft.vanderbilt.edu/guidessub-pages/flipping-the-classroom/.

[30] S. G. Ceylaner and F. Karakus, "Effects of the flipped classroom model on students' self-directed learning readiness and attitudes towards the English course," English Language Teaching, vol. 11, no. 9, pp. 129-143, 2018.

[31] K. Clark, "The effects of the flipped model instruction on student engagement and performance in the secondary mathematics classroom," Journal of Educators Online, vol. 12, no. 1, pp. 91-115, 2015.

[32] K. Baranovic, "Flipping the first-year composition classroom: Slouching toward the pedagogically hip," Doctoral dissertation, Southeast Missouri State University, Cape Girardeau, MO, USA, 2013.

[33] J. Mehring, "An exploratory study of the lived experiences of Japan undergraduate EFL students in the flipped classroom," Unpublished Doctoral Dissertation, Pepperdine University, Malibu, CA, USA, 2015.

[34] A. Zarei and M. Asadi Amani, "The effect of online learning tools on L2 reading comprehension and vocabulary learning," Journal of Teaching Language Skills (JTLS), vol. 37, no. 3, pp. 211-238, 2018.

[35] F. Khodaparast and N. Ghafournia, "On the effect of online/ offline approaches on vocabulary achievement," International Journal of Educational Research, vol. 3, no. 9, pp. 269-280, 2015.

[36] M. Mahmoudi, "The effect of online learning on grammatical accuracy among EFL upper-intermediate learners," Journal of Language Teaching and Research, vol. 11, no. 6, pp. 1011-1016, 2020.

[37] S. Abbasi, A. Chalak, and H. Heidari Tabrizi, "Impact of online strategies-based instruction on Iranian advanced EFL learners' speaking scores," Journal of Modern Research in English Language Studies, vol. 8, no. 3, pp. 51-71, 2021.

[38] K. Khoiriyah, "Flipping the classroom to enhance EFL students' listening skill," Journal of English and Foreign Languages, vol. 11, no. 1, pp. 21-41, 2021.

[39] Z. Rezai Fard, M. Shahrokhi, and M. Talebinejad, “The effect of flipped classroom on Iranian ESP students' vocabulary learning, retention and attitude," International Journal of Foreign Language Teaching and Research, vol. 9, no. 35, pp. 115-129, 2021.

[40] I. Sudarmaji, A. A. Amaliyah Anwar, and A. Mulyana, "Developing students' speaking skills through flipped classroom model on high school students," Journal of English Education and Teaching (JEET), vol. 5, no. 2, pp. 188-200, 2021.
[41] A. Hashemifardnia, S. Shafiee, F. Rahimi Esfahani, and M. Sepehri, "Effects of flipped instruction on Iranian intermediate EFL learners' speaking complexity,accuracy, and fluency," Cogent Education, vol. 8, no. 1, Article ID 1987375 , 2021.

[42] P. Rajabi, K. Mahmoodi, and S. A. Hosseini, "Flipped classroom model and its impact on Iranian EFL learners' classroom anxiety and listening performance," ComputerAssisted Language Learning Electronic Journal (CALL-EJ), vol. 22, no. 3, pp. 1-16, 2021.

[43] N. Asadi, F. Khodabandeh, and R. R. Yekta, "Comparing and contrasting the interactional performance of teachers and students in traditional and virtual classrooms of advanced writing course in distance education university," The Turkish Online Journal of Distance Education, vol. 20, no. 4, pp. 135-148, 2019.

[44] H. Abaeian and L. Samadi, "The effect of the flipped classroom on Iranian EFL learners' L2 reading comprehension: focusing on different proficiency levels," Journal of Applied Linguistics and Language Research, vol. 3, no. 6, pp. 295-304, 2016.

[45] A. Sarani, M. Jalil Zarei, and H. Navidinia, "Effect of online flipped classroom on students' writing development at senior high school," Journal of English language Teaching and Learning, vol. 12, no. 26, pp. 495-515, 2020.

[46] S. Thornbury, How to Teach Vocabulary, Longman, London, UK, 2002, https://www.amazon.com/How-TeachVocabulary-Jeremy-Harmer/dp/0582429668.

[47] B. Harris, J. Harris, L. Reed, and M. Zelihic, "Flipped classroom: Another tool for your pedagogy tool box," Developments in Business Simulation and Experiential Learning, vol. 1, no. 43, pp. 325-333, 2016.

[48] K. Fulton, "Upside down and inside out: flip your classroom to improve student," Learning and Leading with Technology, vol. 39, no. 6, pp. 12-17, 2012.

[49] A. Noroozi, E. Rezvani, and A. Ameri, "Students' perceptions of the incorporation of flipped learning into L2 grammar lessons," Teaching English with Technology, vol. 21, no. 1, pp. 112-130, 2021.

[50] L. Harasim, Learning Theory and Online Technologies. Routledge/Taylor and Francis, New York, NY, USA, 2012.

[51] A. D. Thierer, How Free Computers Are Filling the Digital Divide, Heritage Foundation, Washington, DC, USA, 2001. 